\title{
Interactions of intestinal mediators in the mode of action of cholera toxin
}

\author{
J. W. PETERSON, YING LU, S. DUNCAN, J. CANTU and A. K. CHOPRA
}

Department of Microbiology and Immunology, University of Texas Medical Branch, Galveston, Texas 77555-1019, USA

\begin{abstract}
Summary. Cholera toxin $(\mathrm{CT})$ and prostaglandin $\mathrm{E}_{2}\left(\mathrm{PGE}_{2}\right)$ increased the synthesis of 3',5'cyclic adenosine monophosphate (cAMP) in rabbit intestinal mucosa, which appeared to be responsible for inducing the release of 5-hydroxytryptamine (5-HT) from enterochromaffin cells into the intestinal lumen. With isolated intestinal cells, CT induced the synthesis of PGE more efficiently from epithelial cells than from lamina propria cells; however, the basal amount of this eicosanoid produced by lamina propria cells was approximately six-fold more than that formed by the epithelial cells. The CT-induced stimulation of arachidonate metabolism appeared to be generalised in nature, as $\mathrm{PGF}_{2 \alpha}$ and leukotrienes were synthesised in addition to $\mathrm{PGE}_{2}$. Injection of dibutyryl cAMP into the intestinal lumen in vivo markedly reduced both basal levels of $\mathrm{PGE}_{2}$, as well as CT-induced levels of $\mathrm{PGE}_{2}$, released into the luminal fluid. Similarly, when biopsy samples of tissue from rabbit intestinal loops, challenged in vivo with dibutyryl cAMP, were washed and incubated in vitro, the amount of $\mathrm{PGE}_{2}$ synthesis remained below basal levels. In contrast, when biopsy samples of normal small intestinal tissue were exposed in vitro to dibutyryl cAMP, $\mathrm{PGE}_{2}$ synthesis increased. Thus, cAMP appeared to down-regulate the levels of intestinal eicosanoids in vivo, despite its innate capacity to evoke $\mathrm{PGE}_{2}$ synthesis from mucosal tissue in vitro. Thus, the data indicate that CT-induced mediators exhibit interactive effects that alter their cellular concentrations, that in turn could affect the biological responses.
\end{abstract}

\section{Introduction}

From a clinical standpoint, cholera is a simple disease of dehydration. We have been striving to learn more about the precise sequence of molecular events and the cells that are responsible for the hyperstimulation of water and electrolyte transport in the intestinal mucosa during the course of this disease. Once these factors are known, strategies for interrupting or reversing the mechanism might be developed to promote absorption of water and electrolytes, at least until patients could receive other therapeutic regimens (e.g., water and electrolyte replacement by the parenteral or oral routes supplemented with broad-spectrum antibiotics).

Cholera toxin (CT) is known to be an enterotoxin that stimulates cells by increasing the synthesis of cAMP, a potent second messenger which is associated with many stimulatory processes occurring in many different cell types. ${ }^{1}$ We are interested in evaluating the role of several other substances that also are increased in concentration after CT treatment. The fact that a substance is increased in CT-treated cells does not automatically indicate that it plays an integral role in altering secretory function or in stimulating intestinal smooth muscle. ${ }^{2}$ Likewise, there is concern about attributing all physiological effects to a single substance, when several have been identified. For example, numerous prostaglandins (PGs) have been identified in several types of cell after exposure to CT. ${ }^{3}$ The CTinduced secretory event is markedly reduced in vivo, as well as in vitro, by indomethacin, a drug known to block the synthesis of PGs. Similarly, it has been demonstrated that 5-hydroxytryptamine (5-HT) also may be involved in the stimulation of intestinal cell physiology. ${ }^{4}$ Specialised cells along the intestinal epithelium, known as enterochromaffin cells, store large amounts of 5-HT in vacuoles, presumably for use in signalling to other cell types when noxious substances are present in the intestinal lumen. ${ }^{5}$ These events are accomplished by a complex network of neurons and neurotransmitters that function beneath the epithelium and provide communication with smooth muscle and other epithelial cells. ${ }^{5}$ Close arterial injection of 5-HT results in stimulation of prostaglandin $\mathrm{E}_{2}\left(\mathrm{PGE}_{2}\right)$ synthesis and stimulation of intestinal secretion. ${ }^{6}$ Furthermore, a combination of 5$\mathrm{HT}_{2}$ and 5- $\mathrm{HT}_{3}$ receptor antagonists (e.g., ketansarin and ICS 205-930) completely blocks CT-induced 
secretion of fluid in ligated intestinal segments in the rat. ${ }^{7}$ Methysergide, a 5- $\mathrm{HT}_{1}$ receptor antagonist, also blocks CT-induced secretion. ${ }^{8}$ Such evidence indicates that 5-HT and neural elements play a role in the pathogenesis of cholera, along with cAMP and $\mathrm{PGE}_{2}$.

\section{Materials and methods}

\section{Reagents}

CT was purchased from List Biological Laboratories (Campbell, CA, USA). Cyclic AMP, 5$\mathrm{HT}$, and $\mathrm{PGE}_{2}$ were purchased from Sigma.

\section{Animal model}

A modification of the intestinal loop model described by De and Chatterje ${ }^{9}$ was used to evaluate the secretory effects of CT and various mediators. Adult New Zealand white rabbits were specific pathogen free (SPF) and were purchased from D and D Rabbitry (Tyler, TX, USA). The rabbits were housed in an SPF animal care facility and were fasted for $24 \mathrm{~h}$ before being anaesthetised with a combination of ketamine $\mathrm{HCl} 35 \mathrm{mg} / \mathrm{kg}$ and xylazine $\mathrm{HCl} 5 \mathrm{mg} / \mathrm{kg}$. All surgical procedures were performed aseptically. The lumen of the small intestine was lavaged with $50-60 \mathrm{ml}$ of warm phosphate-buffered saline (PBS) injected into the duodenal region and expelled through a $0 \cdot 25$-in latex tube inserted at the ileo-caecal junction. The small intestine was ligated into $5-\mathrm{cm}$ segments with $2-\mathrm{cm}$ interspaces. All substances were injected into the lumen of the loops in a volume of $1 \mathrm{ml}$, and the duration of the experiments in vivo was $16 \mathrm{~h}$. The animals were over-anaesthetised with an intravenous 100-mg dose of Nembutal (Abbott Laboratories, North Chicago, IL, USA). At post-mortem examination, the volume of fluid accumulating within each loop was divided by the length of the respective loop.

\section{Tissue preparation}

Mucosal tissue from each loop was scraped from the serosa into trichloracetic acid (TCA) $7 \cdot 5 \%$ containing $0 \cdot 1 \mathrm{M} \mathrm{HCl}$. The TCA extracts were assayed for cAMP. ${ }^{10}$ PGE $_{2}$ levels in the intestinal fluids were measured. ${ }^{11}$ Intestinal fluids or PBS lavages from negative loops were similarly extracted for cAMP. In addition, 1-ml samples of intestinal fluid, before centrifugation, were mixed with $14.5 \mu \mathrm{l}$ of $7 \mathrm{~N}$ perchloric acid. The perchloric acid extracts were stored in amber microfuge tubes at $-70^{\circ} \mathrm{C}$ in the dark before measurement of 5-HT. In loops that contained no fluid, a 10-ml lavage with PBS was performed.

\section{Assays for 5-HT, $P G E_{2}$ and cAMP}

Perchloric acid extracts of intestinal fluid $(200 \mu \mathrm{l})$ were injected into a Waters HPLC fitted with a $5-\mu \mathrm{m}$ C18 column (Vydac, Hespera, CA, USA). The column was pumped at a rate of $1 \mathrm{ml} / \mathrm{min}$ with Pump A $(26 \%)$ containing methanol. Pump B $(74 \%)$ contained a solution ( $\mathrm{pH} \mathrm{2.75)}$ of $0.05 \mathrm{M} \mathrm{Na}_{2} \mathrm{HPO}_{4}, 0.03 \mathrm{M}$ citric acid, $0.1 \mathrm{~mm}$ EDTA, and sodium octyl sulphate $0.042 \%$ as described previously. ${ }^{12}$ On this column, 5-HT eluted at $7.5 \mathrm{~min}$, while other tryptophan metabolites-5-hydroxytryptophan, 5-hydroxyindole acetic acid, tryptophan and melatonin-typically eluted at $5 \cdot 1,5 \cdot 5,10.6$ and $14.3 \mathrm{~min}$, respectively. Standard amounts of 5-HT down to $20 \mathrm{pg}$ were detected with a Waters 470 fluorescence detector programmed for an excitation wavelength of $285 \mathrm{~nm}$ and an emission wavelength of $340 \mathrm{~nm}$.

The $\mathrm{PGE}_{2}, \mathrm{PGF}_{2 \alpha}$ and leukotriene content of the intestinal fluids was measured by radioimmunoassay with kits (Perseptive Diagnostics Inc., Cambridge, MA, USA). Samples were extracted as recommended by the manufacturer. The level of cAMP in mucosal tissue extracts and in intestinal fluid was assayed by a radiometric assay with protein kinase, as described previously. ${ }^{10}$

\section{Biopsy of mucosal tissue and in-vitro incubation}

Mucosal biopsies were taken from the rabbit small intestine with an 8-mm biopsy tool, either with or without in-vivo exposure of $15-\mathrm{cm}$ intestinal segments to CT $2 \mu$ g or dibutyryl cAMP $100 \mathrm{mg}$ for $4 \mathrm{~h}$. Mucosal

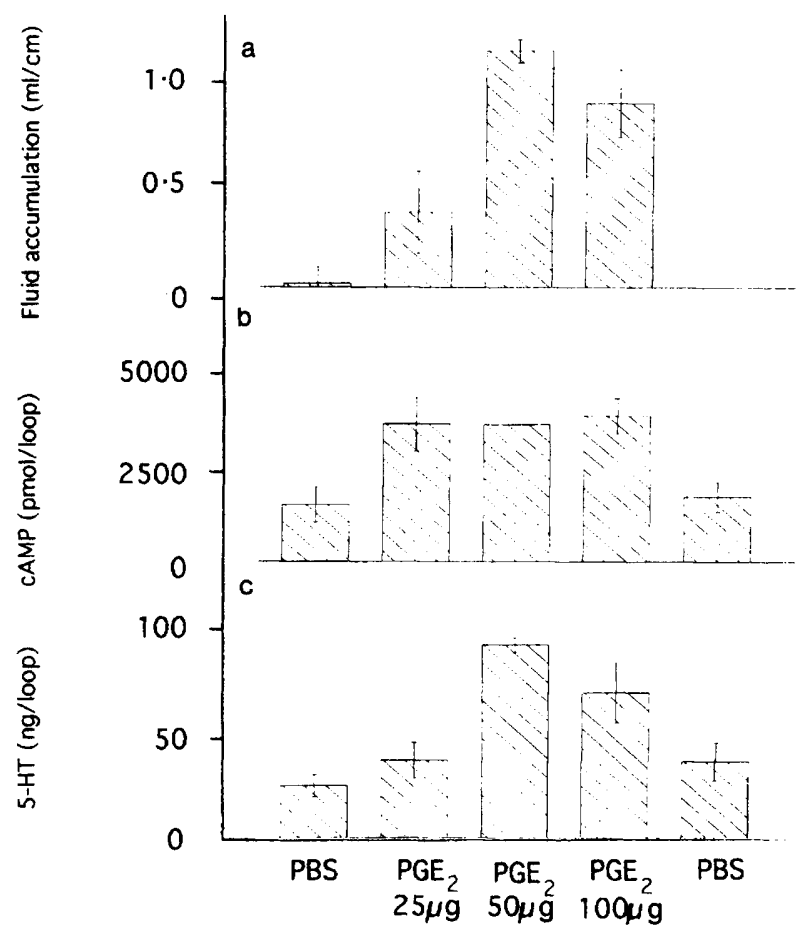

Fig. 1. Effect of increasing doses of $\mathrm{PGE}_{2}$ injected into ligated intestinal loops of six adult rabbits. Panel a depicts the mean fluid accumulation values $(\mathrm{ml} / \mathrm{cm})$ at $16 \mathrm{~h}$. Panels $\mathbf{b}$ and $\mathbf{c}$ indicate the respective amounts of cAMP and 5-HT accumulating in the fluid from intestinal loops. The vertical bars show one standard error above and below the mean. 


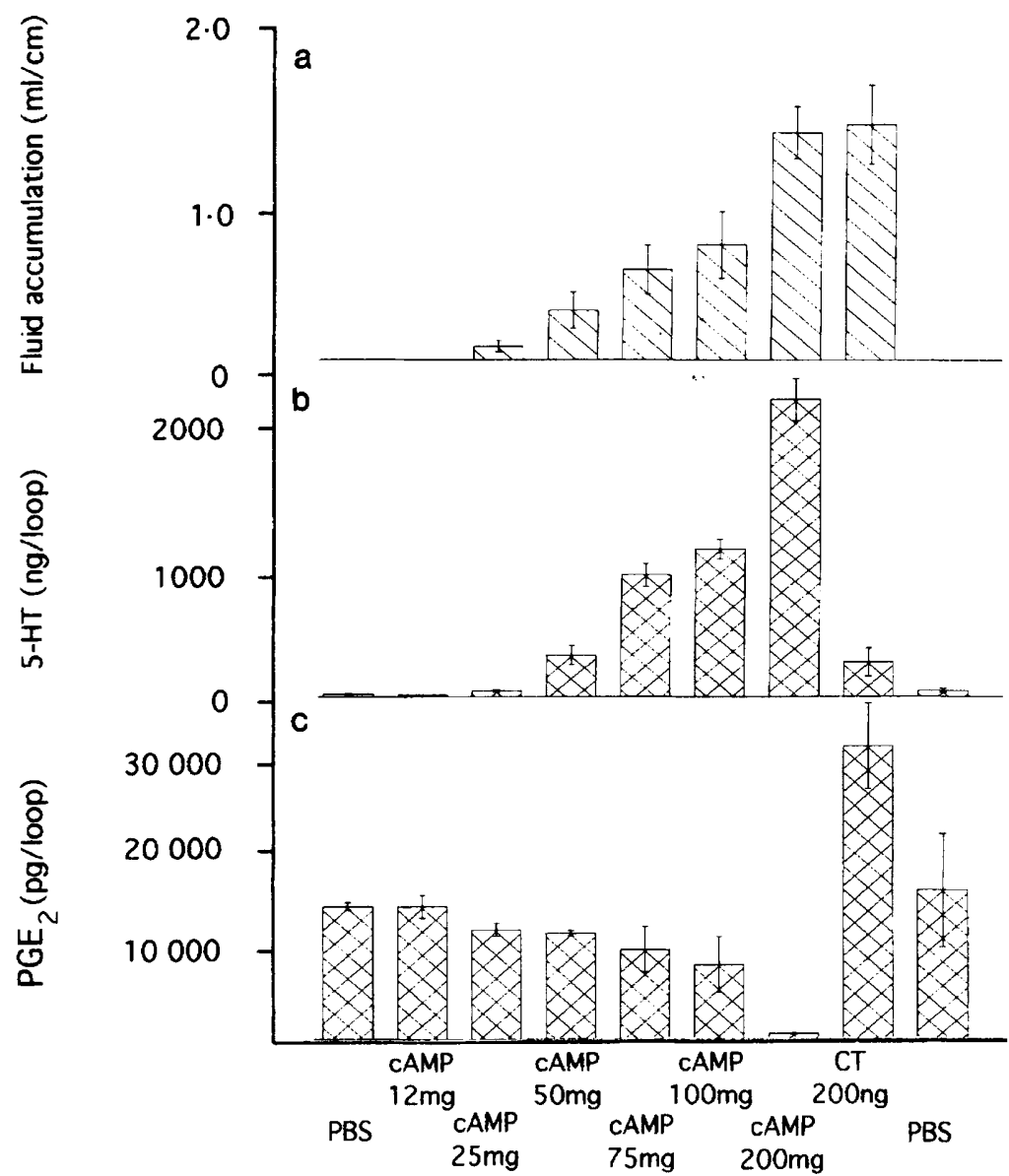

Fig. 2. Effect of increasing amounts of dibutyryl cAMP on fluid accumulation in rabbit intestinal loops after $16 \mathrm{~h}$. Panel a shows the fluid accumulation values $(\mathrm{ml} / \mathrm{cm})$; panels $\mathbf{b}$ and $\mathbf{c}$ illustrate the mean $5-\mathrm{HT}$ and $\mathrm{PGE}_{2}$ responses in the resulting fluid in each intestinal loop. Responses to CT are included as a positive control. The vertical bars show one standard error above and below the mean.

biopsies were washed with PBS before incubating in six-well tissue-culture plates (two tissue samples/well), and $2 \mathrm{ml}$ of Ham's F-12 medium, containing fatty acid-free BSA $0 \cdot 1 \%$, was then added to each well. Mucosal biopsies from normal intestinal tissue were then incubated at $37^{\circ} \mathrm{C}$ in vitro with $\mathrm{CT} 0.5 \mu \mathrm{g} / \mathrm{ml}$ or dibutyryl $250 \mu \mathrm{M}$ cAMP for a period of $18 \mathrm{~h}$. Subsequently, $\mathrm{PGE}_{2}$ levels in the culture medium and in mucosal scrapings of the biopsies were determined as described above.

\section{Isolation of intestinal cells}

In an attempt to determine the type of intestinal cell(s) producing $\mathrm{PGE}_{2}$, the intestinal epithelial cells were separated from the intestinal mucosa by the method of Weiser. ${ }^{13}$ This method consisted of timed washings in PBS, containing $0.5 \mathrm{~mm}$ dithiothreitol and $1.5 \mathrm{~mm}$ EDTA. The remaining intact tissue consisted of denuded villi and lamina propria, which were scraped into PBS. After washing three times with PBS, the cells were suspended in $2 \mathrm{ml}$ of Ham's F12 medium with fetal bovine serum $10 \%$. Cell suspensions were adjusted to $100 \mathrm{Klett}$ units and were incubated overnight $(18 \mathrm{~h})$ with CT $0.5 \mu \mathrm{g} / \mathrm{ml}$. At that time, the culture medium, as well as the TCA $7.5 \%$ extracts of the cells, were assayed for $\mathrm{PGE}_{2}$.

\section{Statistics}

Data were analysed by an analysis of variance and subsequently by the Tukey test for multiple group comparisons. Student's $t$ test was used where only two independent groups were compared (e.g., fig. 5).

\section{Results}

Fig. 1a illustrates the effect of increasing doses of $\mathrm{PGE}_{2}$ on fluid accumulation in small intestinal loops in the adult rabbit model. The lowest concentration of $\mathrm{PGE}_{2}$ that could elicit any fluid accumulation after intraluminal injection was $25 \mu \mathrm{g} / \mathrm{ml}(\mathrm{p}>0.05)$, and the maximal fluid accumulation response occurred with $50 \mu \mathrm{g} / \mathrm{ml}(\mathrm{p}<0.05)$. Corresponding increases in cAMP and 5-HT concentrations in the luminal fluid are shown in fig. $1 \mathrm{~b}$ and $1 \mathrm{c}$, respectively. The small increase in 5-HT at the 25- $\mu$ g dose of $\mathrm{PGE}_{2}(\mathrm{p}>0.05)$ correlated better than the corresponding increase in cAMP ( $p<0.05$ ) with the amount of fluid accumulating in the intestinal loop. Fig. 2 a shows the amount of fluid accumulation elicited by increasing doses of dibutyryl cAMP. Fluid accumulation was considered significant at the $100-\mathrm{mg}$ dose $(\mathrm{p}<0.05)$. Fluid accumulation caused by $200 \mathrm{mg}$ of dibutyryl cAMP was 
Table. In-vivo effect of CT and dibutyryl cAMP on synthesis and release of selected eicosanoids into intestinal fluid with the adult rabbit ligated loop model

\begin{tabular}{lccc}
\hline & \multicolumn{3}{c}{ Mean (SD) eicosanoid concentration } \\
Treatment & \multicolumn{3}{c}{ (pg/loop) } \\
\cline { 2 - 4 } & $\mathrm{PGE}_{2}$ & $\mathrm{PGF}_{2 \alpha}$ & LTC $_{4}$ \\
\hline PBS & $15139(5936)^{*}$ & $21325(7373)$ & $38440(7656)$ \\
CT 2 $\mu \mathrm{g}$ & $29899(9870)$ & $57520(12621)$ & $74040(2070)$ \\
cAMP 100 $\mu \mathrm{g}$ & $4461(1062)$ & $13157(7260)$ & $20050(5760)$ \\
\hline
\end{tabular}

* Arithmetic means (and SD of the mean) were derived from six rabbits.

similar to that caused by $200 \mathrm{ng}$ of CT (fig. 2a). Luminal injection of dibutyryl cAMP also caused a dose-dependent increase in the release of 5-HT from the enterochromaffin cells that was significant at the $75-\mathrm{mg}$ dose $(\mathrm{p}<0 \cdot 05$ ) (fig. $2 \mathrm{~b}$ ). In contrast, injection of dibutyryl cAMP into the loops did not increase $\mathrm{PGE}_{2}$ levels $(p>0.05)$ in the intestinal fluid above that of the control (fig. 2c). $\mathrm{PGE}_{2}$ levels decreased as the dose of dibutyryl cAMP was increased (highest dose; $\mathrm{p}<0.05$ ).

In a previous study we reported that exposure of Chinese hamster ovary cells to CT resulted in a generalised stimulatory effect on arachidonate metabolism, such that several PGs were synthesised. ${ }^{3}$ The table indicates that $\mathrm{CT}$ induced the synthesis and release of $\mathrm{PGF}_{2 \alpha}, \mathrm{PGE}_{2}$ and leukotrienes into the intestinal fluid; however, cAMP depressed the amount of each eicosanoid below basal levels. Thus, the intestinal cell response to CT challenge in vivo is similar to that of non-intestinal cells in invoking a generalised eicosanoid response. ${ }^{3}$

To learn more about the responsiveness of the intestinal mucosa to stimulation by combinations of CT-induced substances, doses of each mediator that elicited maximal fluid accumulation were selected. $\mathrm{PGE}_{2}$ and dibutyryl cAMP were injected into ligated rabbit intestinal loops alone and in combination to assess their effects on the intestinal response (fig. 3). The data in fig. 3a indicate that both $100 \mu \mathrm{g}$ of $\mathrm{PGE}_{2}$

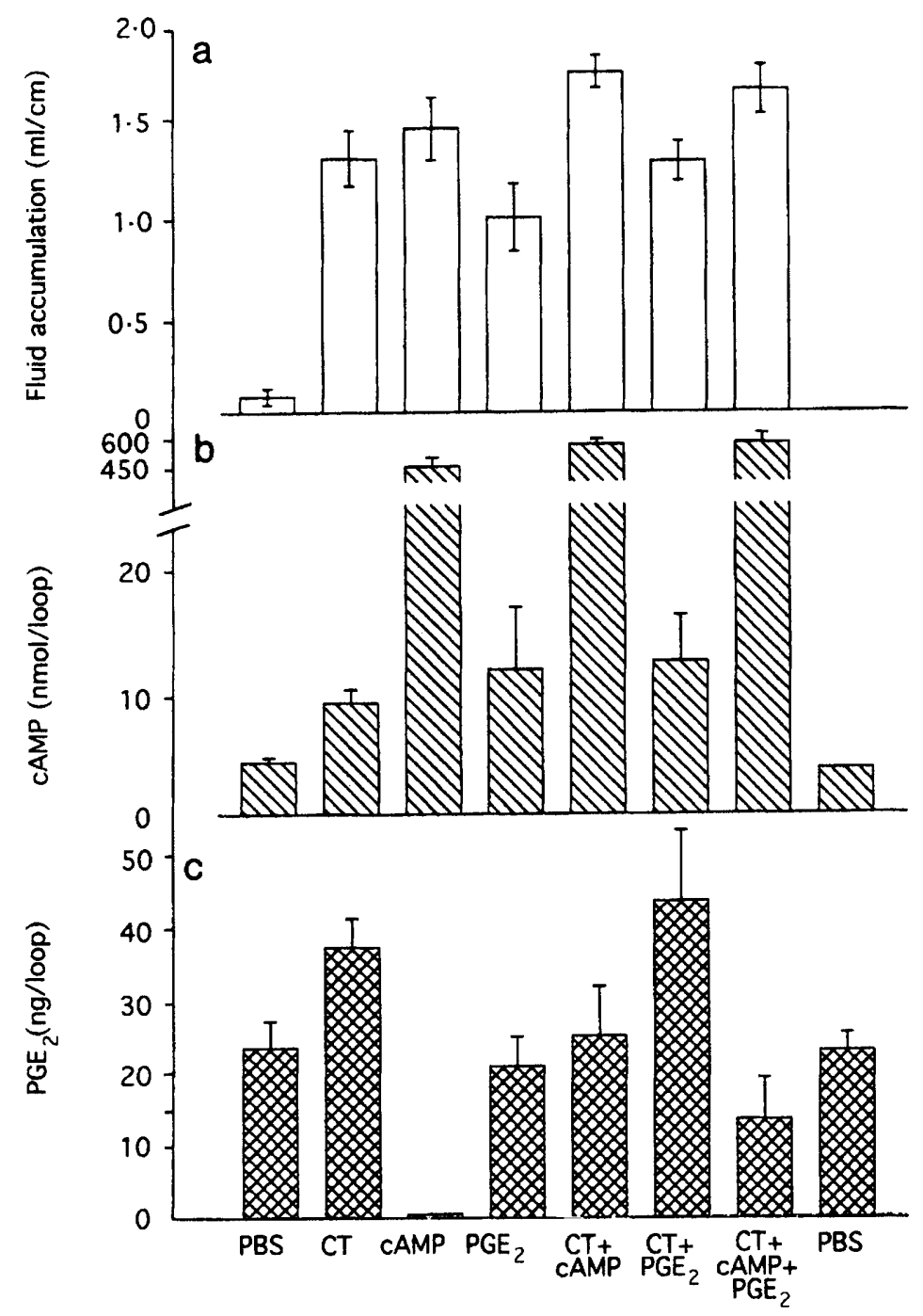

Fig. 3. Effect of combinations of CT with dibutyryl cAMP and $\mathrm{PGE}_{2}$ after injection into rabbit intestinal loops at $16 \mathrm{~h}$. Panel a depicts the mean fluid accumulation values $(\mathrm{ml} / \mathrm{cm})$ from a total of six rabbits. Panels $\mathbf{b}$ and $\mathbf{c}$ show the amount of $\mathrm{cAMP}$ and PGE $_{2}$ accumulating in the intestinal fluid. 


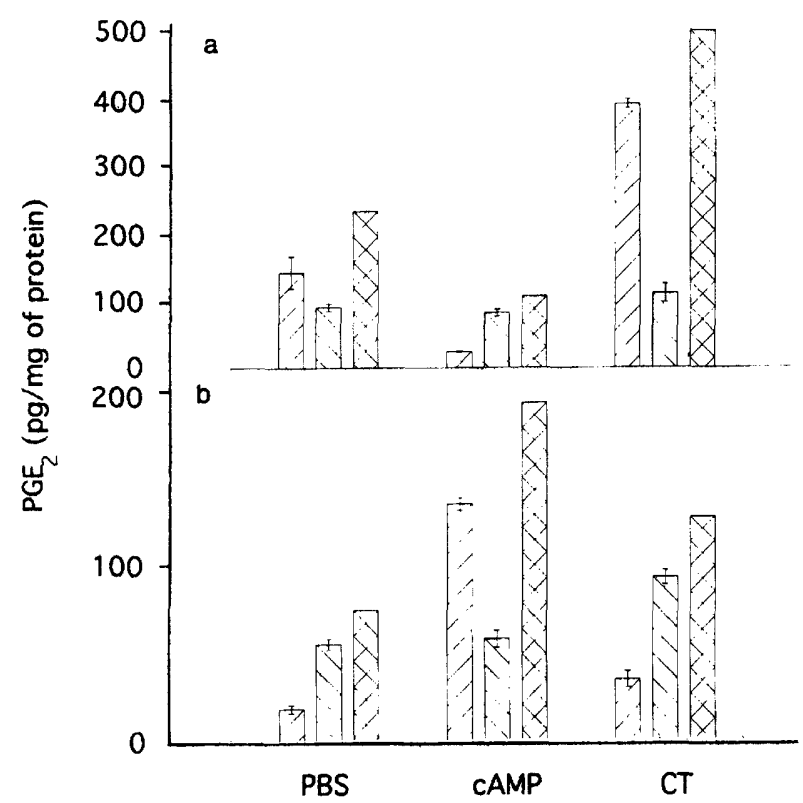

Fig. 4. Amount of $\mathrm{PGE}_{2}$ secreted into the culture medium from small intestinal biopsies. Panel a shows the 18 -h in-vitro $\mathrm{PGE}_{2}$ responses of mucosal biopsies taken from rabbit intestinal loops inoculated with PBS, CT or dibutyryl cAMP for $4 \mathrm{~h}$. In contrast, panel b depicts the in-vitro effects of PBS, dibutyryl cAMP or CT on $\mathrm{PGE}_{2}$ synthesis in mucosal biopsies from normal rabbit small intestine. Levels of $\mathrm{PGE}_{2}$ in tissue culture medium and in the cell extracts were determined. The vertical bars show one standard error above and below the mean. $\square$, intracellular $\mathrm{PGE}_{2} ; \square$, culture medium $\mathrm{PGE}_{2} ; \otimes$, total $\mathrm{PGE}_{\mathbf{2}}$.

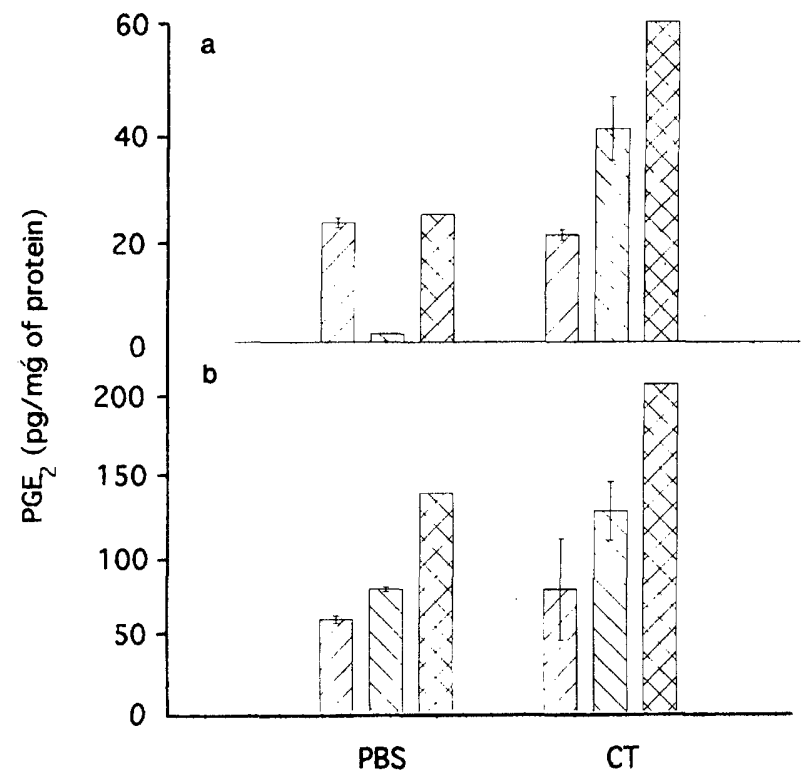

Fig. 5. Synthesis of $\mathrm{PGE}_{2}$ in epithelial cells compared to that in lamina propria cells isolated from normal rabbit small intestine. Levels of $\mathrm{PGE}_{2}$ in tissue culture medium and in the cell extracts were determined after $18 \mathrm{~h}$. The vertical bars show one standard error above and below the mean. $\nabla$, intracellular $\mathrm{PGE}_{2} ; 刃$, culture medium $\mathrm{PGE}_{2} ; \otimes$, total $\mathrm{PGE}_{2}$.

and $200 \mathrm{mg}$ of dibutyryl cAMP evoked substantial amounts of fluid accumulation of the same magnitude as $200 \mathrm{ng}$ of CT $(\mathrm{p}<0 \cdot 05)$. When $\mathrm{PGE}_{2}$ was combined with a dose of $C T$, sufficient to cause a maximal fluid accumulation response, no significant increase $(\mathrm{p}>$ 0.05 ) in fluid accumulation was evident (fig. 3a). One interpretation of these data was that $\mathrm{CT}$ and $\mathrm{PGE}_{2}$ might share a common action, or else additional fluid accumulation should have been formed through an alternate mechanism. Clearly, both $\mathrm{CT}$ and $\mathrm{PGE}_{2}$ elevated cAMP levels $(\mathrm{p}<0.05)$ in the intestinal fluid (fig. 3b), although the amount of mucosal cAMP was not additive when $\mathrm{CT}$ and $\mathrm{PGE}_{2}$ were combined (fig. $3 b)$. We noted again that dibutyryl cAMP diminished basal levels of mucosal $\mathrm{PGE}_{2}$ synthesis $(p<0.05)$, as well as $\mathrm{PGE}_{2}$ levels in any loop exposed to $C T$ (fig. 3c).

Fig. 4 depicts the results of experiments to evaluate $\mathrm{PGE}_{2}$ synthesis in intestinal mucosal biopsy specimens in response to CT or dibutyryl cAMP. Fig. 4a shows the in-vitro synthesis of $\mathrm{PGE}_{2}$ from mucosal biopsies taken from intestinal loops exposed previously in vivo to CT, dibutyryl cAMP or PBS for $4 \mathrm{~h}$. Each tissue sample was then washed and incubated for $18 \mathrm{~h}$ in vitro, after which the amount of $\mathrm{PGE}_{2}$ inside the cells, as well as in the culture medium, was measured. The data (fig. 4a) indicate that prior in-vivo exposure to CT resulted in increased synthesis of $\mathrm{PGE}_{2}(\mathrm{p}<0.05)$, but most was not released from the mucosa. In contrast, in-vivo exposure to dibutyryl cAMP caused an apparent decrease in $\mathrm{PGE}_{2}$ synthesis below basal levels (fig. 4a). These in-vitro data complemented our observation that dibutyryl cAMP failed to stimulate $\mathrm{PGE}_{2}$ synthesis in vivo (figs. $2 \mathrm{c}, 3 \mathrm{c}$ and table). Fig. $4 \mathrm{~b}$ illustrates the effect of in-vitro exposure of mucosal biopsies from normal rabbit intestinal tissue to CT, dibutyryl cAMP or PBS on PGE $_{2}$ synthesis. It was apparent that dibutyryl cAMP elicited the synthesis of $\mathrm{PGE}_{2}$ in mucosal biopsies from normal rabbit intestine $(p<0.05)$. The stimulatory effect of CT on $\mathrm{PGE}_{2}$ synthesis was apparent but not considered significant by the Tukey test $(p>0.05)$.

Fig. 5a illustrates the typical response of isolated intestinal epithelial cells from normal rabbit small intestine to in-vitro challenge with $\mathrm{CT}$ compared to the PBS control. The data indicated that $\mathrm{PGE}_{2}$ was formed by the isolated epithelial cells and released into the culture medium (fig. 5a) after incubation in vitro with CT $(p<0.05)$. A similar, but lower PGE $_{2}$ response $(p>0.05)$, was observed when lamina propria cells were exposed to CT (fig. 5b). Although the basal PGE $_{2}$ levels in the lamina propria cells were approximately six-fold higher than that in the isolated intestinal epithelial cells (fig. $5 \mathrm{a}$ and b), both cell types appeared to have the capacity to synthesise $\mathrm{PGE}_{2}$ in vitro in response to $\mathrm{CT}$.

\section{Discussion}

This study has examined the role of selected mediators in the pathogenesis of experimental cholera. Dibutyryl cAMP and $\mathrm{PGE}_{2}$ elicited fluid accumulation responses that were typical of CT. Massive doses $(200 \mathrm{mg} / \mathrm{ml})$ of dibutyryl cAMP (fig. 2a) were required to cause fluid accumulation equivalent to $\mathrm{CT}$, although such concentrations were not physiological. Our earlier experiments ${ }^{11}$ had indicated that dibutyryl cAMP did not cause fluid accumulation; however, in 
the current experiments the rabbit intestinal loop was modified by extensive lavage of the intestinal lumen with warm PBS to remove residual debris from the intestinal lumen before construction of the loops. In contrast, the effective dose of $\mathrm{PGE}_{2}$ was $25-50 \mu \mathrm{g} / \mathrm{ml}$ (fig. 1a). Considering that luminal administration of this paracrine hormone was not the normal physiological site of action, this dose was relatively low. Beubler et $a l .{ }^{6}$ demonstrated with the rat intestinal loop model that close arterial infusion of ng amounts of $\mathrm{PGE}_{2}$ caused fluid secretion. Because $\mathrm{PGE}_{2}$ induced the synthesis and release of cAMP and 5-HT (fig. 1b and $\mathrm{c}$ ), it could be presumed that the $\mathrm{PGE}_{2}$-induced increase in cAMP levels caused the release of 5-HT from the enterochromaffin cells, just as cAMP induced 5-HT release (fig. 2b).

The relationship between cAMP and $\mathrm{PGE}_{2}$ was intriguing in that in-vivo challenge of intestinal loops with dibutyryl cAMP decreased the basal levels of $\mathrm{PGE}_{2}$ in intestinal fluid. Addition of dibutyryl cAMP to loops challenged with $\mathrm{CT}$ also diminished the $\mathrm{PGE}_{2}$ concentration to levels below that of the controls. These data did not support the concept that cAMP signalled the synthesis of $\mathrm{PGE}_{2}$ in cells exposed to CT, even though in-vitro experiments with Chinese hamster ovary cells and a murine macrophage/monocyte cell line demonstrated that dibutyryl cAMP could evoke PGE $_{2}$ synthesis. ${ }^{3}$ The in-vitro stimulation of $\mathrm{PGE}_{2}$ synthesis by dibutyryl cAMP (fig. $4 \mathrm{~b}$ ) was in striking contrast to that observed in vivo (figs. $2 \mathrm{c}$ and $3 \mathrm{c})$ and the in-vitro responses of mucosal biopsies from dibutyryl cAMP-treated loops (fig. 4a). These observations suggested that the intestinal mucosal response to dibutyryl cAMP, in synthesising $\mathrm{PGE}_{2}$, depended on whether the mucosal tissue was intact and connected to the vasculature. In addition, our data suggested that intestinal cells behaved differently from other cells with regard to the production of CTstimulated mediators. A possible interpretation of the data shown in figs. 2c, 3c, 4a and the table is that cAMP served to decrease $\mathrm{PGE}_{2}$ synthesis or enhance its degradation in vivo. Considering these data, it is difficult to perceive cAMP as an intermediate leading to the synthesis of this eicosanoid in vivo, were it not for the innate capacity of the isolated intestinal cells to synthesise $\mathrm{PGE}_{2}$ in response to $\mathrm{CT}$ in vitro.

As indicated by earlier studies with non-intestinal cells, ${ }^{3}$ the intestinal eicosanoid response to CT appeared to be generalised, as CT stimulated the synthesis of $\mathrm{PGF}_{2 \alpha}$ and leukotrienes, as well as of $\mathrm{PGE}_{2}$ (table). Very little information is available about leukotriene synthesis in response to CT. Triadafilopoulos et al. ${ }^{14}$ determined that the cytotoxic enterotoxin from Clostridium difficile induced the synthesis of $\mathrm{PGE}_{2}$, as well as leukotriene $\mathrm{B}_{4}\left(\mathrm{LTB}_{4}\right)$ in the rabbit intestinal loop model. They included CT as one of their controls, which increased the synthesis of $\mathrm{PGE}_{2}$, but not $\mathrm{LTB}_{4}$. We observed that $\mathrm{CT}$ stimulated the synthesis of leukotrienes, although the RIA kits used could not determine the specific type, because of their structural similarity. The RIA kit from Perseptive Diagnostics reacted with $\mathrm{LTA}_{4}, \mathrm{LTB}_{4}$, $\mathrm{LTC}_{4}$ and $\mathrm{LTD}_{4}$, but not with PGs. Based on these data, CT might be expected to elicit the synthesis of several arachidonate metabolites, due to the availability of arachidonate released from phosphatidylinositol. ${ }^{15}$ In the latter study, it was established that CT increased the hydrolysis of this minor phospholipid component, releasing free arachidonate and glycerophosphatidyl inositol from a murine macrophage/monocyte cell line.

In conclusion, the data in this report provide a basis for understanding the mechanism of action of CT. Clearly, CT increases cAMP levels in virtually any cell to which it is exposed, ${ }^{1}$ and earlier reports indicate that cAMP levels in the epithelial cell monolayer increase with little increase in cAMP in the lamina propria. ${ }^{10}$ Cyclic AMP elicits the release of 5HT (fig. 2) from enterochromaffin cells, which are located in the epithelium, thereby activating the enteric nervous system..$^{4-8,16,17}$ This concept is based, in part, upon the inhibitory effect that neural blockade with lidocaine, tetrodotoxin and hexamethonium have on CT-induced secretion. ${ }^{5,18}$ Further, 5-HT antagonists diminish the secretory response. ${ }^{7,8}$ Evidence indicates that the 5-HT released from the basal portion of the enterochromaffin cells initiates a signal that is transmitted via the enteric neurons to the crypt epithelial cells. The physiological effects include increases in intestinal ion transport, that ultimately result in loss of water and electrolytes into the intestinal lumen. The role of $\mathrm{PGE}_{2}$ is implied by the capacity of indomethacin to block the CT-induced fluid accumulation response and the correlation of the eicosanoid synthesis (figs. 4 and 5) in intestinal cells with that of secretion. ${ }^{3,6,11,18,19}$ It is possible that eicosanoids could be involved in the post-neural signalling leading to secretion of fluid from crypt epithelial cells. Finally, the elevation in epithelial cell cAMP can result from the ADP-ribosylating enzymatic activity characteristic of $\mathrm{CT}$, that can directly stimulate chloride secretion in the epithelial cells. ${ }^{1}$ The precise role of each of these possible mechanisms in the pathogenesis of cholera is still very difficult to delineate, and it is likely that multiple factors and cell types are involved following exposure to CT. 


\section{References}

1. Moss J, Vaughn M. Cholera toxin and E. coli enterotoxins and their mechanisms of action. In: Hardegree MC, Tu AT (eds) Handbook of natural toxins, vol 4, Bacterial toxins. New York, Marcel Dekker Inc. 1988: 39-87.

2. Mathias JR, Clench MH. Alterations of small intestine motility by bacteria and their enterotoxins. In: Wood JD (ed) Handbook of physiology-the gastrointestinal system (section 6), Ist edn, vol 1. Bethesda, American Physiological Society. 1989: 1153-1177.

3. Peterson JW, Jackson CA, Reitmeyer JC. Synthesis of prostaglandins in cholera toxin-treated Chinese hamster ovary cells. Microb Pathog 1990; 9: 345-353.

4. Nilsson O, Cassuto J, Larsson P-A et al. 5-hydroxytryptamine and cholera secretion: a histochemical and physiological study in cats. Gut $1983 ; 24: 542-548$.

5. Eklund S, Cassuto J, Jodal M, Lundgren O. The involvement of the enteric nervous system in the intestinal secretion evoked by cyclic adenosine 3',5'-monophosphate. Acta Physiol Scand 1984; 120: 311-316.

6. Beubler E, Bukhave K, Rask-Madsen J. Significance of calcium for the prostaglandin $E_{2}$-mediated secretory response to 5hydroxytryptamine in the small intestine of the rat in vivo. Gastroenterology 1986; 90: 1972-1977.

7. Beubler E, Horina G. $5-\mathrm{HT}_{2}$ and $5-\mathrm{HT}_{3}$ receptor subtypes mediate cholera toxin-induced intestinal fluid secretion in the rat. Gastroenterology 1990; 99: 83-89.

8. Sjöqvist A, Cassuto J, Jodal M, Lundgren O. Actions of serotonin antagonists on cholera-toxin-induced intestinal fluid secretion. Acta Physiol Scand 1992; 145: 229-237.

9. De SN, Chatterje DN. An experimental study of the mechanism of action of Vibrio cholerae on the intestinal mucous membrane. J Pathol Bacteriol 1953; 66: 559-562.

10. Peterson JW, Molina NC, Houston CW, Fader RC. Elevated cAMP in intestinal epithelial cells during experimental cholera and salmonellosis. Toxicon 1983; 21 : 761-775.
11. Peterson JW, Ochoa L. Role of prostaglandins and cAMP in the secretory effects of cholera toxin. Science 1989; 245 : 857-859.

12. Chapin DS, Lookingland KJ, Moore KE. Effects of LC mobile phase composition on retention times for biogenic amines, and their precursors and metabolites. Current Separations 1986; 7: 68-70.

13. Weiser MM. Intestinal epithelial cell surface membrane glycoprotein synthesis. J Biol Chem 1973; 248: 2536-2541.

14. Triadafilopoulos G, Pothoulakis C, Weiss R, Giampaolo C, LaMont JT. Comparative study of Clostridium difficile toxin A and cholera toxin in rabbit ileum. Gastroenterology 1989; 97: 1186-1192.

15. Burch RM, Jelsema C, Axelrod J. Cholera toxin and pertussis toxin stimulate prostaglandin $\mathrm{E}_{2}$ synthesis in a murine macrophage cell line. J Pharmacol Exp Ther 1988; 244: 765-773.

16. Cassuto J, Jodal M, Tuttle R, Lundgren O. 5hydroxytryptamine and cholera secretion: physiological and pharmacological studies in cats and rats. Scand $J$ Gastroenterol 1982; 17: 695-703.

17. Eklund S, Brunsson I, Jodal M, Lundgren O. Changes in cyclic $3^{\prime}, 5^{\prime}$-adenosine monophosphate tissue concentration and net fluid transport in the cat's small intestine elicited by cholera toxin, arachidonic acid, vasoactive intestinal polypeptide and 5-hydroxytryptamine. Acta Physiol Scand 1987; 129: 115-125.

18. Sjöqvist A, Cassuto J, Jodal M, Brunsson I, Lundgren O. The effect on intestinal fluid transport of exposing the serosa to hydrochloric acid. A study of mechanisms. Acta Physiol Scand 1982; 116: 447-454.

19. Van Loon FPL, Rabbani GH, Bukhave K, Rask-Madsen J Indomethacin decreases jejunal fluid secretion in addition to luminal release of prostaglandin $\mathrm{E}_{2}$ in patients with acute cholera. Gut 1992; 33: 643-645. 